\title{
Lactococcus lactis carrying the pValac DNA expression vector coding for IL-10 reduces inflammation in a murine model of experimental colitis
}

\author{
Meritxell Zurita-Turk ${ }^{1 \dagger}$, Silvina del Carmen ${ }^{2 \dagger}$, Ana CG Santos ${ }^{3}$, Vanessa B Pereira ${ }^{1}$, Denise C Cara ${ }^{4}$, \\ Sophie Y Leclercq ${ }^{5}$, Alejandra dM de LeBlanc ${ }^{2}$, Vasco Azevedo ${ }^{1}$, Jean-Marc Chatel ${ }^{6}$, Jean G LeBlanc ${ }^{2}$ \\ and Anderson Miyoshi ${ }^{*}$
}

\begin{abstract}
Background: Inflammatory bowel diseases (IBD) are intestinal disorders characterized by inflammation in the gastrointestinal tract. Interleukin-10 is one of the most important anti-inflammatory cytokines involved in the intestinal immune system and because of its role in downregulating inflammatory cascades, its potential for IBD therapy is under study. We previously presented the development of an invasive strain of Lactococcus lactis (L. lactis) producing Fibronectin Binding Protein A (FnBPA) which was capable of delivering, directly to host cells, a eukaryotic DNA expression vector coding for IL-10 of Mus musculus (pValac:il-10) and diminish inflammation in a trinitrobenzene sulfonic acid (TNBS)-induced mouse model of intestinal inflammation. As a new therapeutic strategy against IBD, the aim of this work was to evaluate the therapeutic effect of two L. lactis strains (the same invasive strain evaluated previously and the wild-type strain) carrying the therapeutic pValac:il-10 plasmid in the prevention of inflammation in a dextran sodium sulphate (DSS)-induced mouse model.
\end{abstract}

Results: Results obtained showed that not only delivery of the pValac:il-10 plasmid by the invasive strain L. lactis MG1363 FnBPA+, but also by the wild-type strain L. lactis MG1363, was effective at diminishing intestinal inflammation (lower inflammation scores and higher IL-10 levels in the intestinal tissues, accompanied by decrease of IL-6) in the DSS-induced IBD mouse model.

Conclusions: Administration of both L. lactis strains carrying the pValac:il-10 plasmid was effective at diminishing inflammation in this murine model of experimental colitis, showing their potential for therapeutic intervention of IBD.

\section{Background}

Inflammatory bowel diseases (IBD), including ulcerative colitis (UC) and Crohn's disease (CD), are characterized by spontaneous and chronic inflammation of the gastrointestinal tract (GIT). Despite much research in the last years, the exact etiology and pathogenesis of these disorders remain unclear; however, it is nowadays generally accepted that IBD are caused by dysregulation of the mucosal immune system in relation to the native intestinal

\footnotetext{
* Correspondence: miyoshi@icb.ufmg.br

${ }^{\dagger}$ Equal contributors

'Department of General Biology, Institute of Biological Sciences, Federal University of Minas Gerais, Belo Horizonte, Brazil

Full list of author information is available at the end of the article
}

microbiota in genetically susceptible individuals [1]. Current treatments for IBD are restricted to the use of anti-inflammatory drugs, immunosuppressants and antibiotics, which although showing moderate therapeutic effect, present serious side effects and reveal that better, cheaper and longer lasting drugs are necessary [2].

Interleukin-10 (IL-10) is one of the most important anti-inflammatory cytokines involved in the intestinal immune system [3] and because of its immunosuppressive activity and its central role in downregulating inflammatory cascades [4] it presents itself as a good therapeutic candidate against IBD [5]. Recombinant human IL-10 raised hope when first used in the 90s in CD 
patients as the treatment led to remission in patients that were otherwise refractory to treatment [6]; however, two large, multi-centered follow-up studies using subcutaneous dosing were unable to confirm the results $[7,8]$. Moreover, systemic treatment with IL-10 showed to be quite limiting because of its short half-life (1.1-2.6 h) and requirement of high protein concentration $(20 \mu \mathrm{g} / \mathrm{kg})$, increasing the cost of production, discomfort and secondary effects in the patients [9]. On the other hand, oral treatment with IL-10 has also shown to be limited due to its extreme sensitivity to the environment of the GIT and therefore survival in it [10].

New approaches to yield more specific delivery of IL10 to the intestinal mucosa and prevent the drawbacks associated to systemic and oral administration led to the development of IL-10-producing Lactococcus lactis (L. lactis) strains [11]. In 2003, a biological containment system for human IL-10-producing L. lactis [12] showed to be safe and improved the disease when tested in CD patients in phase I clinical trials [13]; however, clinical results did not reveal a statistically significant difference in mucosal healing between patients receiving the recombinant strains and placebo.

Since this strain produces IL-10 and releases it in the GIT, its clinical use for IBD is still hindered by IL-10's sensitivity and poor survival in these hostile conditions. In this regard, a new eukaryotic DNA expression vector for delivery using lactococci, called pValac, which allows cloning of an ORF (Open Reading Frame) of interest, expression of the molecule by host cells, replication both in E. coli and in L. lactis and selection of bacteria, was firstly constructed in 2009 [14]. Its potential to deliver DNA and trigger DNA expression by epithelial cells has already been demonstrated in vitro [15] and in vivo [16]. This strategy does not only fulfil the aforementioned advantages, but also combines the advantages of mucosal immunity, safety of using non-pathogenic bacteria, technique simplicity and low cost of DNA therapy. Moreover, ingested $L$. lactis strains pose no risk to the individuals as these bacteria are quickly degraded and only around 20$30 \%$ reach the sites of inflammation, their transit through the gastrointestinal tract takes between 2 to 3 days and they are incapable of multiplying in the body or become part of the normal gut flora.

Our research group recently evaluated a recombinant invasive L. lactis strain expressing the Staphylococcus aureus Fibronectin Binding Protein A (FnBPA), harbouring the eukaryotic DNA expression vector pValac coding for the anti-inflammatory cytokine IL-10 of Mus musculus (L. lactis MG1363 FnBPA + pValac:il-10), for in situ expression of IL-10 and therefore higher, more efficient and direct production of this cytokine at the sites of inflammation. This strategy showed to be efficient at diminishing inflammation in a TNBS-induced inflammatory mouse model [17].

The aim of the present work was to evaluate and compare the therapeutic capacity of two L. lactis strains, the invasive $L$. lactis MG1363 FnBPA + strain and the wt $L$. lactis MG1363, both carrying the pValac:il-10 plasmid, for the prevention of experimental IBD in a DSS-induced mouse model.

\section{Methods}

\section{Bacterial strains, growth conditions and plasmid}

The bacterial strains used in this work are listed in Table 1. E. coli TG1 was aerobically grown in Luria-Bertani (LB) medium at $37^{\circ} \mathrm{C}$ with vigorous shaking whereas all $L$. lactis [18] strains were grown in M17 medium (Difco, Sparks, MD, USA) supplemented with $0.5 \%$ glucose (GM17) at $30^{\circ} \mathrm{C}$ without shaking. Recombinant $E$. coli were selected by addition of $10 \mu \mathrm{g} / \mathrm{mL}$ chloramphenicol (Cm) while recombinant L. lactis were selected by addition of $10 \mu \mathrm{g} /$ $\mathrm{mL} \mathrm{Cm}$ and/or $5 \mu \mathrm{g} / \mathrm{mL}$ of erythromycin (Ery). For animal trials, L. lactis cultures grown until an $\mathrm{OD}_{600}$ of 1.0-1.2 were previously stocked in glycerol $80 \%(1: 4)$ and on day of use they were centrifuged in order to eliminate any remaining traces of the antibiotic and medium and resuspended in $100 \mu \mathrm{L}$ of saline solution $(0.15 \mathrm{M} \mathrm{NaCl})$ for animal feedings.

As previously shown by del Carmen and co-workers, the pValac:il-10 plasmid harbours an eukaryotic region containing the CytoMegaloVirus promoter (pCMV), the IL-10 ORF of Mus musculus and the polyadenylation signal of bovine growth hormone (BGH polyA), required for gene expression by eukaryotic host cells, as well as a prokaryotic region containing the $\mathrm{RepA} / \mathrm{RepC}$ replication origins for both $E$. coli and L. lactis, respectively, and a $\mathrm{Cm}$ resistance gene for bacterial selection [14].

\section{DNA manipulations}

General DNA manipulation techniques were carried out according to standard procedures. Unless otherwise indicated, DNA restriction and modification enzymes were used as recommended by the suppliers. DNA fragments were isolated from agarose gels using the Illustra GFX PCR DNA and Gel Band Purification Kit (GE Healthcare Life Sciences, Chalfont St. Giles, UK). PCR amplifications were performed using AccuPrimePfx DNA Polymerase (Invitrogen, Carlsbad, CA, USA) and/or GoTaq DNA Polymerase (Invitrogen, Carlsbad, CA, USA) in a DNA thermocycler (MJ Research, Inc., Minnesota, USA). Plasmid DNA from E. coli and L. lactis was isolated as previously described [19] with the following modifications: for plasmid DNA extraction from $L$. lactis, the first step included addition of TES (25\% sucrose, $1 \mathrm{mM}$ EDTA, 50 mMTris$\mathrm{HCl}, \mathrm{pH} 8)$ containing lysozyme $(10 \mathrm{mg} / \mathrm{mL})$ for $30 \mathrm{~min}$ at $37^{\circ} \mathrm{C}$ to prepare protoplasts. Electroporation of $E$. coli and 
Table 1 Bacterial strains used in this work

\begin{tabular}{|c|c|c|}
\hline Bacterial Strain & Characteristics & Reference \\
\hline $\begin{array}{l}\text { Escherichia coli } \\
\text { (E.coli) TG1 }\end{array}$ & $\begin{array}{l}\text { [supE, hsd, } \Delta 5 \text {, thi, } \\
\Delta \text { lac-proAB), F'(traD36 } \\
\text { proAB-lacZ } \Delta M 15)]\end{array}$ & $\begin{array}{l}\text { Invitrogen (São Paulo, } \\
\text { Brazil) }\end{array}$ \\
\hline $\begin{array}{l}\text { Escherichia coli } \\
\text { (E.coli) TG1 } \\
\text { (pValac:il-10) }\end{array}$ & $\begin{array}{l}\left(p C M V / C m^{R} / \operatorname{RepA} /\right. \\
\operatorname{Rep}(/ / L-10)\end{array}$ & {$[17]$} \\
\hline $\begin{array}{l}\text { Lactococcus lactis } \\
\text { (L. lactis) MG1363 }\end{array}$ & L. lactis subsp. cremoris & $\begin{array}{l}\text { Laboratory of Cellular } \\
\text { and Molecular Genetics } \\
\text { (LGCM), Federal } \\
\text { University of Minas } \\
\text { Gerais (UFMG), Brazil }\end{array}$ \\
\hline $\begin{array}{l}\text { Lactococcus lactis } \\
\text { (L. lactis) MG1363 } \\
\text { pValac:il-10 }\end{array}$ & $\begin{array}{l}\text { L. lactis MG1363 strain } \\
\text { carrying the pValac:il-10 } \\
\text { plasmid }\end{array}$ & This work \\
\hline $\begin{array}{l}\text { Lactococcus lactis } \\
\text { (L. lactis) MG1363 } \\
\text { FnBPA }\end{array}$ & $\begin{array}{l}\text { L. lactis MG1363 strain } \\
\text { expressing FnBPA of } \\
\text { S. aureus }\end{array}$ & [19] \\
\hline $\begin{array}{l}\text { Lactococcus lactis } \\
\text { (L. lactis) MG1363 } \\
\text { FnBPA pValac:il-10 }\end{array}$ & $\begin{array}{l}\text { L. lactis MG1363 strain } \\
\text { expressing FnBPA of } \\
\text { S. aureus carrying the } \\
\text { pValac:il- } 10 \text { plasmid }\end{array}$ & {$[17]$} \\
\hline
\end{tabular}

L. lactis was performed as previously described [20]. E. coli transformants were plated on LB agar plates containing the required antibiotic for $24 \mathrm{~h}$ at $37^{\circ} \mathrm{C}$, whereas L. lactis transformants were plated on GM17 agar plates containing the required antibiotic and were counted after 2-days incubation at $30^{\circ} \mathrm{C}$.

\section{Induction of intestinal inflammation and feeding procedure in mice}

Conventional female C57BL/6 mice [21] weighing approximately $18 \mathrm{~g}$, obtained from the inbred closed colony (CEBIO) maintained at the Federal University of Minas Gerais (UFMG - Belo Horizonte, Brazil), were used to evaluate the therapeutic effect of L. lactis MG1363 pValac: il-10 and L. lactis MG1363 FnBPA + pValac:il-10 in the prevention of intestinal inflammation in a DSS-induced mouse model. Procedures and manipulation of animals followed the rules of the ethics and research committees of the Biological Institute of the UFMG and all animal protocols were approved by the Ethics Committee on Animal Experiments (CETEA). All animals were maintained in collective cages (6 animals/cage) in an environmentally controlled room with a 12-hour light/dark cycle and unlimited free access to water (or DSS solution) and food. After acclimatization for 17 days, colonic inflammation was induced by the addition of 1.5\% (w/v) DSS (MW 40,00050,000; USB Affymetrix, Santa Clara, CA, USA) in drinking water for 7 consecutive days. Liquid consumption was monitored to ensure that all mouse groups consumed similar volumes $(4 \pm 2 \mathrm{~mL})$ of the DSS solution daily. For experimental procedure, mice were divided in 6 experimental groups: i) control group which received $100 \mu \mathrm{l} \mathrm{NaCl}$ intragastrically while no DSS was added to the drinking water; ii) DSS group which received $100 \mu \mathrm{NaCl}$ intragastrically while DSS was added to the drinking water and iii) L. lactis MG1363 group (wt group), iv) L. lactis MG1363 pValac:IL-10 group, v) L. lactis MG1363 FnBPA + group and vi) L. lactis MG1363 FnBPA + pValac: il-10 group, which all received intragastrically $100 \mu \mathrm{l}$ of the corresponding bacterial strain as suspension, at a dose of $2 \times 10^{9} \mathrm{CFU} / 100 \mu \mathrm{l}$, in $\mathrm{NaCl}$. The intragastric administration of $\mathrm{NaCl}$ or the bacterial suspensions was once daily since the day before the beginning of DSS administration until sacrifice. At day 9, mice were sacrificed by cervical dislocation for organ collection.

\section{Macroscopic and microscopic (histological) assessment of intestinal inflammation}

On the day of sacrifice (day 9), colons were removed, excised and visually inspected for macroscopic evaluation to assess colonic inflammation [disease activity index (DAI)], using a scoring system in which the following features were graded: body weight loss ( 0 , no loss; 1,1 5\% loss; 2, 5-10\% loss; 3, 11-15\% loss and 4, >15\% loss), diarrhoea ( 0 , absent; 2 , moderate; 4 , severe) and rectal bleeding ( 0 , absent; 2 , moderate; 4 , severe). The macroscopic damage score was calculated from the score of all clinical signs with a maximum score of 12 . For histological inflammation scoring [histological activity index (HAI)], samples of the colon were fixed in 10\% formalin in phosphate-buffered saline (PBS), embedded in paraffin, cut into $3-5-\mu \mathrm{m}$ sections and stained with haematoxylin-eosin (H\&E-staining) for microscopic analysis. These sections were blindly scored based on a semi quantitative scoring system previously described [22] in which the following features were graded: extent of destruction of the mucosa's architecture ( 0 , normal; 1,2 and 3, light, moderate and extensive damage, respectively), presence and degree of cellular infiltration ( 0 , normal; 1,2 and 3 , light, moderate and transmural infiltration, respectively), extent of muscle thickening ( 0 , normal; 1,2 and 3 , light, moderate and extensive thickening, respectively), presence or absence of crypt abscesses ( 0 , absent and 1 , present) and the presence or absence of goblet cell depletion ( 0 , absent and 1 , present). The histological damage score was calculated as the addition of the scores corresponding to each feature. High macroscopic and histological damage scores indicate increased damage in the intestines.

\section{Secretory $\lg A(\operatorname{sg} A)$ assay}

Levels of sIgA in the intestinal fluid were determined by enzyme linked immunosorbent assay (ELISA) as previously described [23]. Briefly, microtitre plates (NUNC, Thermo Scientific, Waltham, MA, USA) were coated with goat anti-mouse UNLB antibody (Southern Biotechnology, 
Birmingham, AL, USA) in coating buffer ( $\mathrm{pH} 9.8$ ) overnight at $4^{\circ} \mathrm{C}$. Wells were then washed with a saline $0.05 \%$ tween solution and blocked with $200 \mu \mathrm{L}$ of PBS with $0.05 \%(\mathrm{w} / \mathrm{v})$ casein for $1 \mathrm{~h}$ at room temperature. The supernatants obtained from the intestinal fluids after centrifugation at $432 \mathrm{~g}$ for $20 \mathrm{~min}$ at $4^{\circ} \mathrm{C}$ and the diluted standards in PBS-0.25\% casein (1:10) were then added to the plate and incubated for 1 hour at $37^{\circ} \mathrm{C}$. After washing, goat anti-mouse IgA HRP (Southern Biotechnology, Birmingham, AL, USA) was added and plates were incubated for $1 \mathrm{~h}$ at $37^{\circ} \mathrm{C}$. The colour reaction was developed at room temperature with the addition of $100 \mu \mathrm{L} /$ well of orthophenylenediamine (OPD) $(1 \mathrm{mg} / \mathrm{mL}$ ) (Sigma, St. Louis, MO, USA), 0.04\% $\mathrm{H}_{2} \mathrm{O}_{2}$ substrate in sodium citrate buffer. The reaction was finally stopped by the addition of $20 \mu \mathrm{L} /$ well of $2 \mathrm{~N} \mathrm{H}_{2} \mathrm{SO}_{4}$. Absorbance was measured at $492 \mathrm{~nm}$ using a Bio-Rad Model 450 Microplate Reader. Results were expressed as concentration $(\mu \mathrm{g} / \mathrm{mL})$, according to the standard curve.

\section{Colon tissue preparation and cytokine assays}

For cytokine assays, colons were weighed and homogenized in PBS containing 0.05\% (v/v) Tween-20, $0.1 \mathrm{mM}$ phenylmethylsulphonyl fluoride, $0.1 \mathrm{mM}$ benzethonium chloride, $10 \mathrm{mM}$ EDTA and $20 \mathrm{KIU}$ AprotininA using a tissue homogenizer $(1 \mathrm{~mL} / 0.1 \mathrm{~g})$. Suspensions were centrifuged at $600 \mathrm{~g}$ for $10 \mathrm{~min}$ at $4^{\circ} \mathrm{C}$ and the supernatants collected for cytokine assay. Concentrations of IL-10, TNF- $\alpha$, IL-6, IL-17 were measured by ELISA as described previously [23]. Briefly, after coating microtitre plates (NUNC, Thermo Scientific, Waltham, MA, USA) with purified monoclonal antibodies reactive to mouse cytokines IL-10, TNF- $\alpha$, IL-6, IL-17 (BD, New Jersey, USA), standards and samples were added and incubated overnight at $4^{\circ} \mathrm{C}$. Biotinylated monoclonal antibodies anti-mouse IL-10, TNF- $\alpha$, IL-6, IL-17 were added and incubated for $1 \mathrm{~h}$ at room temperature, after which peroxidase-labelled streptavidin (Sigma, St. Louis, MO, USA) was added. A colour reaction was developed at room temperature with $100 \mu \mathrm{L} /$ well of OPD $(1 \mathrm{mg} / \mathrm{mL})$ and $0.04 \% \mathrm{H}_{2} \mathrm{O}_{2}$ substrate in sodium citrate buffer. The reaction was stopped by the addition of $20 \mu \mathrm{L} /$ well of $2 \mathrm{~N} \mathrm{H}_{2} \mathrm{SO}_{4}$. Absorbance was measured at $492 \mathrm{~nm}$ using a Bio-Rad Model 450 Microplate Reader. Results were expressed as concentration of each cytokine $(\mathrm{pg} / \mathrm{mL})$, according to the respective standard curve.

\section{Statistical analysis}

Statistical analyses were performed using the GraphPad Prism 5.0 software (San Diego, CA, USA) and all results were expressed as mean \pm standard deviation (SD). Significance of differences among groups was assessed by Student's t-test or analysis of variance (ANOVA) followed by a Tukey comparison post-hoc test. Means were considered statistically different when $\mathrm{p}<0.05$.

\section{Results}

\section{Construction of L. lactis MG1363 pValac:il-10}

The pValac:il-10 plasmid was previously constructed by del Carmen and co-workers and used to construct the invasive L. lactis MG1363 FnBPA + pValac:il-10 strain. This strain was tested in an experimental IBD mouse model induced by TNBS and showed to diminish inflammation and damage scores [17]. In this work, we constructed the non-invasive L. lactis MG1363 pValac:il10 strain; the construction was confirmed by PCR (data not shown). This strain was tested together with the invasive strain in the experimental IBD mouse model induced by DSS.

\section{L. lactis strains carrying the pValac:il-10 plasmid show anti- inflammatory properties in the DSS-induced colitis in mice} DSS is a well-established animal model of mucosal inflammation that has been used for over two decades in the study of IBD pathogenesis and preclinical studies [8] and when administrated in drinking water induces an acute inflammation. C57BL/6 mice were used for the DSS study as these animals are highly susceptible to DSS-induced colitis and do not naturally recover from this disease [21].

Similar to the results previously obtained in a TNBSinduced colitis mouse model, $L$. lactis MG1363 FnBPA + pValac:il-10 was also capable of diminishing inflammation in the DSS-induced colitis mouse model (Figures 1 and 2). It was also observed that the non-invasive variant, $L$. lactis MG1363 pValac:il-10, was also capable of decreasing the inflammation in this model. Overall, both groups that received the L. lactis strains carrying the pValac:il-10 (pValac: il-10 groups) showed a lower DAI (Figure 1) and therefore significant decrease of inflammation, when compared to the DSS control group and the groups receiving $L$. lactis MG1363 and L. lactis MG1363 FnBPA+, which presented more diarrhoea and bleeding, which was almost absent in animals from the pValac:il-10 groups. The colon length of each animal was also measured as a marker of inflammation-caused injury. As expected, there was a significant shortening of the colon induced by DSS treatment $(6.92 \mathrm{~cm})$, and the administration of L. lactis MG1363 $(6.96 \mathrm{~cm})$ or L. Lactis MG1363 FnBPA + $(6.93 \mathrm{~cm})$ did not improve it. However, the pValac:il-10 groups showed a significant improvement in colon length, L. lactis MG1363 pValac:il-10 $(7.97 \mathrm{~cm})$ and L. lactis MG1363 FnBPA pValac:il-10 $(8.01 \mathrm{~cm})$, when compared to the other groups induced with DSS, resembling more the colon lengths of the control group $(8.16 \mathrm{~cm})$. Regarding body weight loss, all groups maintained similar weight during the 8 days of experiment (data not shown). 


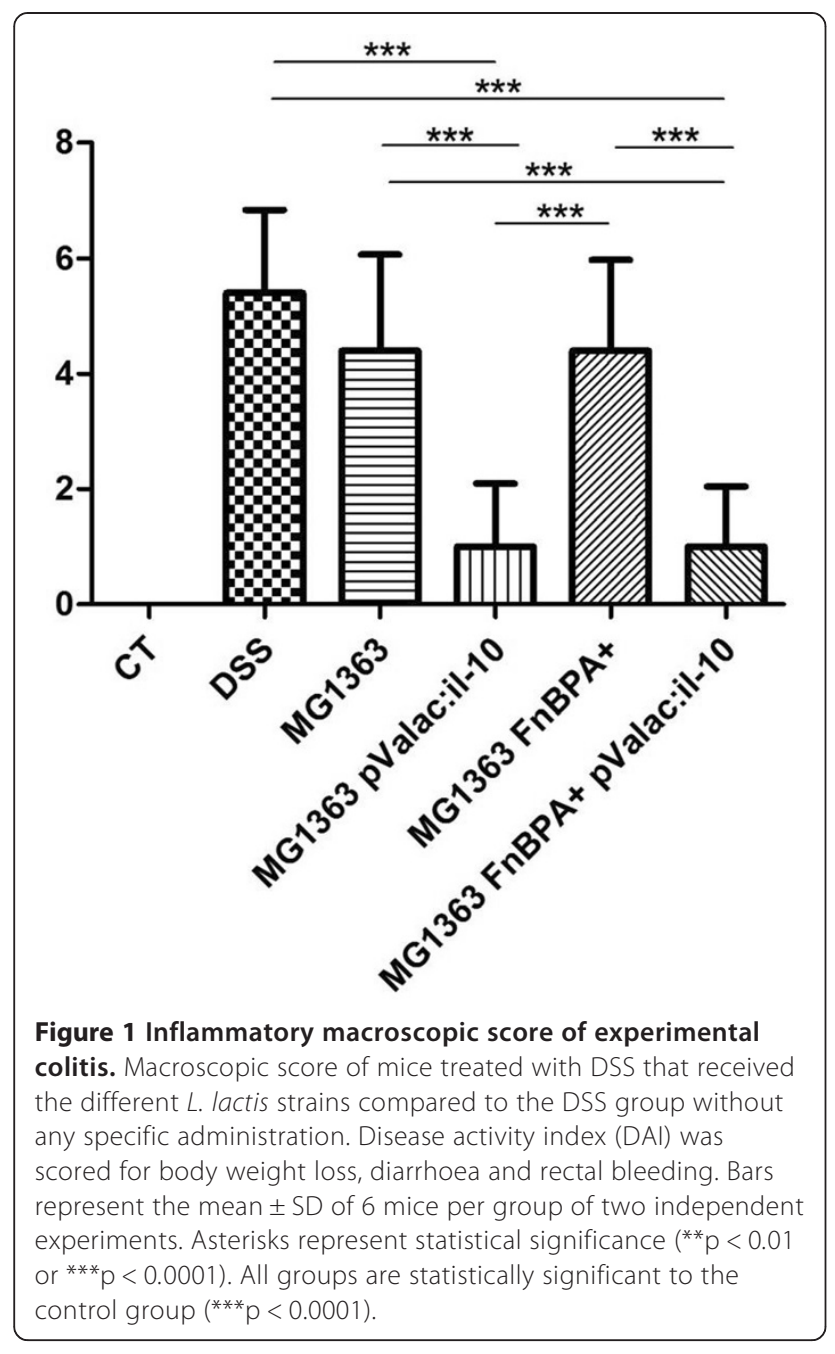

To evaluate the colons microscopically, a HAI was performed for all groups, and showed that animals from the pValac:il-10 groups presented a significant decrease of the damage score when compared to the DSS group and the mice that received L. lactis MG1363 or L. lactis MG1363 FnBPA + (Figure 2A).

Histologically, all samples from the colon of healthy control mice (group without DSS treatment) presented themselves within normal standards. The architecture integrity of the colon was maintained, with goblet cells, thin submucosa without signs of congestion or oedema and absence of inflammatory infiltrate in the mucosa and submucosa (Figure 2B). On the other hand, the colitis control group (DSS group, Figure $2 \mathrm{C}$ ) presented intense alteration in the mucosal architecture of their colons, with areas of intense ulceration, absence of glands in large parts of the mucosa and accentuated depletion of goblet cells. It was also possible to observe crypt abscesses and the submucosa was marked by an intense oedema and inflammatory infiltrate constituted principally by macrophages. Moreover, thickening of the muscle layer was also observed. No significant differences were observed when animals received L. lactis MG1363 (Figure 2D) or L. lactis MG1363 FnBPA + (Figure 2F) strains, compared to the DSS treated control. However, groups that received L. lactis MG1363 pValac:il-10 (Figure 2E) or L. lactis MG1363 FnBPA + pValac:il-10 (Figure 2G) presented a milder pathological picture, with tendency to normality, a smaller compromised area and a reduction in the intensity of the lesion. Reduced inflammatory infiltrates without erosion of the epithelium, light oedema and diminished depletion of goblet cells, partially preserving the mucosal architecture, were also observed.

\section{The pValac:il-10 plasmid increases the production of secretory $\lg \mathrm{A}$}

Secretory IgA creates a first-line of defence against mucosal compromise that is lost during IBD. Therefore, sIgA levels from intestinal fluids of mice were also analysed. It was observed that only mice that received the L. lactis MG1363 FnBPA + pValac:il-10 strain showed a significant increase in the concentration of sIgA when compared to those from the control group, DSS group and the groups that did not receive the strains carrying the pValac:il-10 plasmid (Figure 3). Moreover, this strain also induced an increased sIgA production when compared to the non-invasive L. lactis MG1363 pValac:il-10 strain.

The administration of L. lactis carrying the pValac:il-10 plasmid modulates the production of cytokines in the intestinal tissues

Administration of DSS to mice leads to a macrophageinduced inflammation and tissue damage accompanied by a cellular cytotoxic-mediated inflammatory response (macrophage/ $\mathrm{T}_{\mathrm{h}} 1 / \mathrm{T}_{\mathrm{h}} 17$ chemotactic profile) during the progression of colitis [24]. In this regard, in order to determine if the pValac:il-10 plasmid could modulate the cytokine level in diseased animal, IL-10, TNF- $\alpha$, IL-6, IL17 were measured from colonic tissues. Mice from the L. lactis MG1363 pValac:il-10 group showed significantly higher IL-10 levels compared with the control group, while animals from the L. lactis MG1363 FnBPA + pValac:il-10 group showed higher IL-10 levels than the animals from the control and DSS groups (Figure 4A). Regarding pro-inflammatory cytokines, TNF- $\alpha$ (Figure 4B) and IL-17 (Figure 4D) levels did not show significant differences between the control and test groups, while IL-6 levels showed significant differences between some of the test and control groups (Figure 4C). IL-6 increased significantly $\left({ }^{*} \mathrm{p}<0.05\right)$ in the DSS group when compared to the control group, and no significant differences with the groups that received L. lactis MG1363 or L. lactis MG1363 FnBPA + were observed. The levels of IL-6 were significantly lower $\left({ }^{* *} \mathrm{p}<0.001\right)$ in the pValac:il-10 groups 


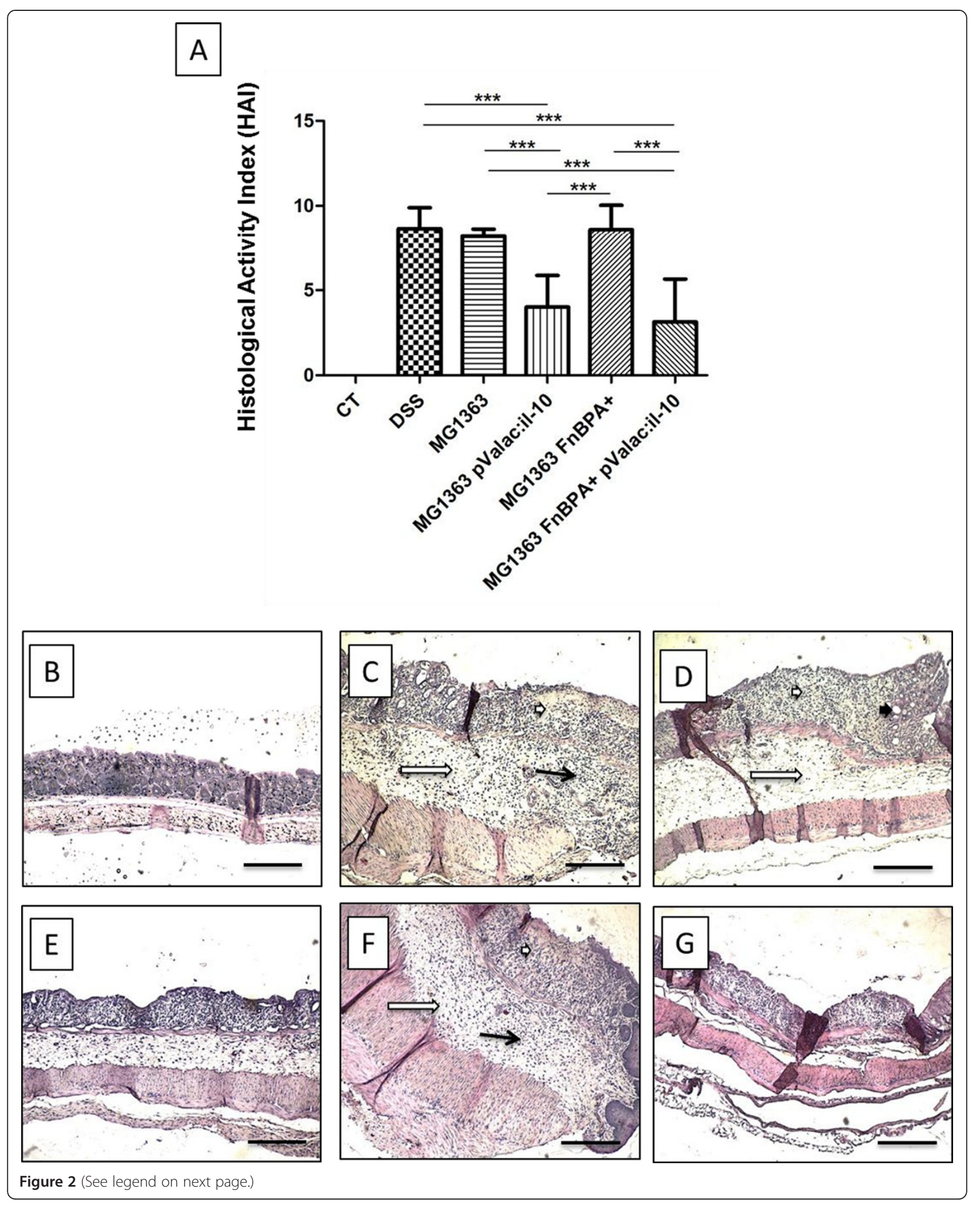




\section{(See figure on previous page.)}

Figure $\mathbf{2}$ Inflammatory microscopic score of experimental colitis and histopathology of intestinal changes between all groups. Macroscopic score of mice treated with DSS that received the different L. lactis strains compared to the DSS group without any specific administration (A). Histological activity index (HAl) was obtained from the colonic tissues stained by H\&E. Bars represent the mean \pm SD of 6 mice per group of two independent experiments. Asterisks represent statistical significance ${ }^{* *} p<0.01$ or $\left.{ }^{* * *} p<0.0001\right)$. All groups are statistically significant to the control group $\left({ }^{* *} \mathrm{p}<0.0001\right)$. Representative photos obtained from the proximal colon of a mouse from control group: Control group (B), DSS group (C), and the groups of mice treated with DSS that received L. lactis MG1363 (D) L. lactis MG1363 pValac:il-10 (E) Proximal colon of diseased mice that received the L. lactis MG1363 FnBPA + (F) or L. lactis MG1363 FnBPA + pValac:il-10 (G). The bar on each image represents $100 \mu \mathrm{m}$. The short white arrows show the depletion of goblet cells; the long white arrow, intense oedema in the submucosa; the short black arrow, crypt abscesses; and the long black arrow, inflammatory infiltrate (especially of macrophages).

compared to the DSS group, resembling the values of the control group.

\section{Discussion}

Interleukin 10's interest in the attempt of developing an efficient therapy against IBD has grown since it was observed that IL-10 knockout (IL-10 $0^{-/-}$) mice develop spontaneous enterocolitis when not maintained in germ-free conditions [25]. Although many advances have been made there still does not exist any treatment for IBD, showing that the major drawback to use IL-10 is its correct administration and directioning to the sites of inflammation.

In order to overcome these problems, new strategies based on local delivery of IL-10 to the intestinal mucosa have been developed; high IL-10 concentration at these

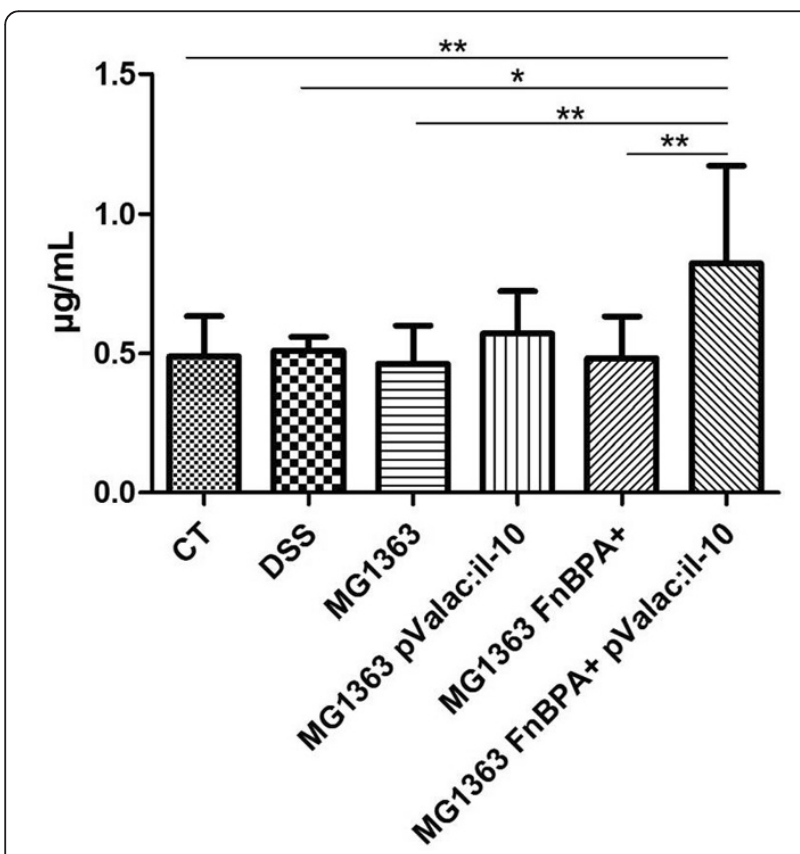

Figure 3 Influence of DSS and different bacterial administrations on gut secretory IgA. Intestinal fluid was collected and total slgA was measured by ELISA of wild-type mice, DSS wild-type mice and diseased mice that received the L. lactis MG1363 strain, L. lactis MG1363 pValac:il-10 strain, L. lactis MG1363 FnBPA + strain or L. lactis MG1363 FnBPA + pValac:il-10 strain during treatment. Bars represent the mean $\mathrm{N}=6 \pm \mathrm{SD}$ of two independent experiments. Asterisks represent statistical significance ${ }^{*} p<0.05$ or ${ }^{* *} p<0.001$ ). sites would outweigh the need for high doses and as such avoid the increase of pro-inflammatory cytokine production and other undesired side effects.

One such strategy consists in the use of polymer-based microparticles. These particles encapsulate gelatine nanoparticles containing plasmid DNA expressing murine IL-10 and are capable of releasing these nanoparticles directly at the desired site of action. These IL-10 gene containing particles have shown to successfully reduce the levels of inflammatory cytokines as well as disease activity scores in the TNBS-induced model of colitis [26]. However, despite promising, scale-up to an industrial level appears to be very expensive and complicated.

Another strategy by Yao and collaborators consists in a Bifidobacterium longum strain capable of secreting human IL-10 which was capable of alleviating inflammatory damage of colonic tissue in a DSS-induced mouse model by blocking the colitis-activated NF- $\kappa B$ pathways and upregulating $\mathrm{CD} 4+\mathrm{CD} 25+$ Foxp3 $+\mathrm{T}_{\text {reg }}$ in blood and mesenteric lymph nodes [27].

As such, in order to improve IL-10 delivery to the sites of inflammation using L. lactis, a L. lactis strain expressing FnBPA [15,28], that has the capacity to efficiently internalize and trigger recombinant DNA expression by human epithelial cells, was used to deliver a eukaryotic expression vector coding for IL-10 of Mus musculus, pValac:il-10, directly to host cells in the GIT for recombinant in situ IL-10 production. This new strategy recently showed to be capable of diminishing inflammation in a TNBSinduced mouse model [17].

Following these results and in order to evaluate the therapeutic effect of the pValac:il-10 plasmid in a larger context, in the present work we explored the potential of this therapeutic plasmid in a DSS-induced mouse model delivered by two L. Lactis strains as a new therapeutic strategy for the prevention of intestinal inflammation. L. lactis MG1363 FnBPA + expresses FnBPA, which confers the strain the capacity to mediate adhesion to host tissue and bacterial uptake by eukaryotic cells. To evaluate if this characteristic results in improved antiinflammatory effect, it was compared with the non-invasive L. lactis MG1363 strain. Our results showed that both strains were capable of delivering the eukaryotic expression vector to host cells directly at the sites of inflammation 


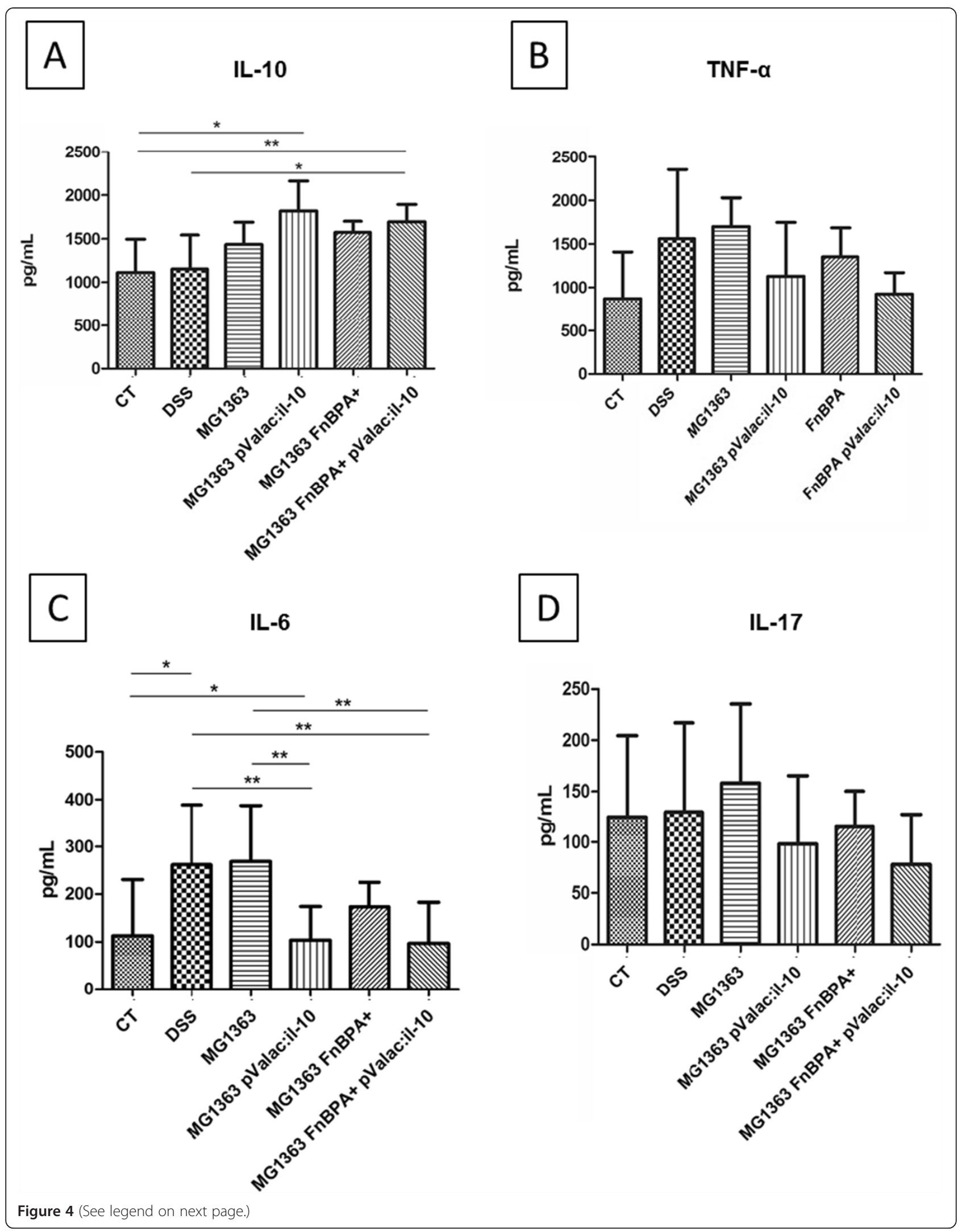


leading to in situ IL-10 production, avoiding strong and undesired side-effects, and diminishing the severity of inflammation by maintaining an anti-inflammatory environment in the gut.

DSS has the intrinsic capacity to disrupt the epithelial cell barrier, causing normal gut substances to activate mucosal macrophages, which in turn produce immunomodulatory cytokines. It is generally accepted that DSS is directly toxic to gut epithelial cells of the basal crypts and affects the integrity of the mucosal barrier [29]. The DSS concentration used in the present model triggered an acute colonic inflammation accompanied by diarrhoea and rectal bleeding and did not lead to mortality. The administration of strains carrying the pValac:il-10 plasmid statistically lowered the macroscopic score compared to the DSS group, regarding diarrhoea and rectal bleeding. No weight loss was observed within the different groups, but this has already been reported earlier [30]. At histological level, administration of strains carrying the pValac: $i l-10$ plasmid were capable of decreasing the severity of inflammation, with tendency to normality, demonstrating the anti-inflammatory effects of this strategy.

IgA is the most abundant immunoglobulin produced, in its secretory form, at mucosal sites. In the luminal mucous layer, SIgA protects the intestinal epithelium against colonization and invasion by pathogens or commensals [31] and therefore helps modulating and controlling inflammation. In our model, no significant decrease of SIgA was associated with the inflammation observed in mice treated with DSS that did not receive the pValac:il-10. The administration of bacteria carrying the pValac:il-10 plasmid was accompanied by significantly increased levels of sIgA only in the intestinal fluid of mice that received the L. Lactis MG1363 FnBPA+ pValac:il-10 strain, compared to the DSS treated mice. Moreover, this strain also induced an increased sIgA production when compared to the L. lactis MG1363 pValac:il-10 strain. We believe that the difference of IgA production induced by these two strains is due to the different cellular entry mechanism these bacteria use after oral administration. In this regard, L. lactis MG1363 FnBPA + pValac:il-10 strain induced increased IgA production because these bacteria invade enterocytes in the epithelium, while L. lactis MG1363 pValac:il-10 are captured by macrophages (as these bacteria have no invasion capacity), which does not directly lead to the induction of IgA. These results showed that the L. Lactis MG1363 FnBPA + pValac:il-10 strain could not only have an anti-inflammatory effect in this model, but also promote the gut immunological barrier by limiting the penetration of bacteria into host tissues and therefore protect mice by helping to modulate inflammation. The expression of FnBPA by this strain might allow for a higher binding capacity and internalization by eukaryotic cells, thus enhancing the production of IL-10 and its anti-inflammatory properties.

Cytokines produced in the gut mucosa greatly influence the resulting immunological outcome; production of anti-inflammatory cytokines induces mucosal tolerance, while high levels of pro-inflammatory cytokines induce inflammation. Since cytokines are major mediators of inflammation and regulatory activity in the gut mucosa, we analysed the ability of L. lactis strains carrying the pValac:il-10 plasmid to modulate the production of cytokines in the colonic tissues of mice. Mice that received the pValac:il-10 plasmid, whether delivered by L. lactis MG1363 or L. lactis MG1363 FnBPA + (pValac:il-10 groups), showed significantly higher IL-10 levels than the control group (healthy mice), probably due to a constant and higher production of IL-10 by the eukaryotic cells of these animals. It is also important to note that the expression of FnBPA by the bacterial strain carrying the pValac:il-10 plasmid was associated to significantly higher IL-10 levels in the intestinal tissues compared to the DSS group, where this cytokine was produced as normal immune response against inflammation. However, these levels of IL-10 were not significantly different from those obtained in the L. lactis MG1363 pValac:il-10 group, nor were associated with significant differences in the levels of the other cytokines tested in both pValac:il-10 groups. The lack of significant difference between both strains carrying the pValac:il-10 plasmid could be explained by the fact that both cellular entry mechanisms used by these bacteria (enterocytes invasion by the invasive strain and capture by macrophages by the non-invasive strains) lead to efficient and similar IL-10 production; however, by different cell types.

Pro-inflammatory cytokines, including TNF- $\alpha$, IL-6 and IL-17, can be produced by $\mathrm{T}$ and $\mathrm{B}$ lymphocytes, macrophages and/or neutrophils, which are massively infiltrated in inflammatory lesions in mice with DSSinduced acute colitis. This DSS colitis switches from a $\mathrm{T}_{\mathrm{h}} 1-\mathrm{T}_{\mathrm{h}} 17$-mediated acute inflammation with increased levels of TNF- $\alpha$, IL- 6 and IL-17, to a predominant $T_{h} 2$ mediated inflammatory response that shows a decrease in TNF- $\alpha$, IL- 6 and IL-17 while increasing levels of antiinflammatory cytokines IL-4 and IL-10 [24]. In our 
experimental acute model, at the time of sacrifice, the results only showed higher IL-6 levels in the DSS group and in the group of mice treated with DSS that received the L. lactis MG1363 strain, when compared to the control group (healthy mice). Significant decrease of this cytokine was observed in the intestinal tissues from mice that received the pValac:il-10 plasmid, compared to the DSS group. These results were associated to the increased IL-10 levels obtained in those animals and confirm the anti-inflammatory capacity of both strains carrying the pValac:il-10 plasmid at modulating the gut immune response.

\section{Conclusions}

The results obtained in the present work confirm and strengthen our previous results that L. lactis MG1363 FnBPA + pValac:il-10 shows to be a good candidate to maintain an anti-inflammatory status in the GIT and diminishing intestinal inflammation. Moreover, we here also showed that not only delivery of the pValac:il-10 plasmid by the invasive strain L. lactis MG1363 FnBPA+, but also by the non-invasive L. lactis MG1363 strain, was effective at diminishing intestinal inflammation, showing that this strategy presents potential for therapeutic intervention of IBD. FnBPA expression was not related to more anti-inflammatory capacity; however, it was associated with significantly higher IL-10 levels in the intestinal tissues when compared to animals from the DSS group. Moreover, the highest levels of SIgA in the intestinal fluid where observed in the animals from the L. lactis MG1363 FnBPA + pValac:il-10 group, showing better immunomodulatory effect by the invasive strain.

\section{Competing interests}

The authors declare that they have no competing interests.

\section{Authors' contributions}

MZT designed the study, carried out the experiments and wrote the paper. SC and ACGS participated with the realization of the experiments and contributed to the scientific discussion. DCCM carried out all histological analyses and contributed with the scientific discussion. SL, AMLB, VA and JGLB helped to draft the manuscript and gave final approval for publication. JMC and AM conceived the study, participated in its design and coordination, helped to draft the manuscript and gave final approval for publication. All authors read and approved the final manuscript.

\section{Authors' information}

Jean G LeBlanc and Anderson Miyoshi Share credit in this work for senior authorship.

\section{Acknowledgements \\ This work was supported by: (i) Conselho Nacional de Desenvolvimento Científico e Tecnológico (CNPq), (ii) Centro Brasileiro-Argentino de Biotecnologia (CBAB), (iii) Coordenação de Aperfeiçoamento de Pessoal de Nível Superior (CAPES), (iv) Consejo Nacional de Investigaciones Científicas y Técnicas (CONICET), (v) Agencia Nacional de Promoción Científica y Tecnológica (ANPCyT) and (vi) Consejo de Investigaciones de la Universidad Nacional de Tucumán (CIUNT).}

\section{Author details}

${ }^{1}$ Department of General Biology, Institute of Biological Sciences, Federal University of Minas Gerais, Belo Horizonte, Brazil. ${ }^{2}$ Reference centre for
Lactobacilli (CERELA-CONICET), San Miguel de Tucumán, Argentina. ${ }^{3}$ Department of Biochemistry and Immunology, Institute of Biological Sciences, Federal University of Minas Gerais, Belo Horizonte, Brazil. ${ }^{4}$ Department of Morphology, Institute of Biological Sciences, Federal University of Minas Gerais, Belo Horizonte, Brazil. ${ }^{5}$ Ezequiel Dias Foundation (FUNED), Belo Horizonte, Brazil. ${ }^{6}$ INRA, UMR1319 Micalis, Domaine de Vilvert, F-78350 Jouy-en-Josas, France.

Received: 8 May 2014 Accepted: 4 August 2014

Published: 9 August 2014

\section{References}

1. Fiocchi C: Inflammatory bowel disease: etiology and pathogenesis. Gastroenterology 1998, 115:182-205.

2. Lakatos L, Lakatos PL: Changes in the epidemiology of inflammatory bowel diseases. Orv Hetil 2007, 148(5):223-228.

3. Asadullah K, Sterry W, Volk HD: Interleukin-10 therapy-review of a new approach. Pharmacol Rev 2003, 55(2):241-269.

4. Mocellin S, Marincola F, Rossi CR, Nitti D, Lise M: The multifaceted relationship between IL-10 and adaptive immunity: putting together the pieces of a puzzle. Cytokine Growth Factor Rev 2004, 15(1):61-76.

5. de Moreno de LeBlanc A, del Carmen S, Zurita-Turk M, Santos Rochat C, van de Guchte M, Azevedo V, Miyoshi A, LeBlanc JG: Importance of IL-10 modulation by probiotic microorganisms in gastrointestinal inflammatory diseases. ISRN Gastroenterol 2011, 1(1):1-10.

6. Van Deventer SJH, Elson CO, Fedorak R: Multiple doses of intravenous interleukin 10 in steroid-refractory crohn's disease. Gastroenterology 1997, 113:383-389.

7. Colombel FF, Rutgeerts P, Malchow H, Jacyna M, Nielsen OH, Rask-Madsen J, Van Deventer S, Ferguson A, Desreumaux P, Forbes A, Geboes K, Melani L, Cohard M: Interleukin 10 (Tenovil) in the prevention of postoperative recurrence of Crohn's disease. Gut 2001, 49:42-46.

8. Schreiber S, Fedorak RN, Nielsen OH: Safety and efficacy of recombinant human interleukin 10 in chronic active Crohn's disease. Crohn's disease IL-10 cooperative study group. Gastroenterology 2000, 119:1461-1472.

9. Van Montfrans C, Van de Ende A, Fedorak RN, Gangl A, Elson CO, Rutgeerts P, Schreiber S, Wild G, Hanauer S, Grint P, Van Deventer SJH: Anti- and proinflammatory effects of interleukin 10 in mild to moderate Crohn's disease. Gastroenterology 1999, 116:A777.

10. Steidler L, Vandenbroucker K: Genetically modified Lactococcus lactis: novel tools for drug delivery. Int J Dairy Technol 2006, 59(2):140-146.

11. Li MC, He SH: IL-10 and its related cytokins for treatment of inflammatory bowel disease. World J Gastroenterol 2004, 10(5):620-625.

12. Steidler L, Neirynck S, Huyghebaert N, Snoeck V, Vermeire A, Goddeeris B, Cox E, Remon JP, Remaut E: Biological containment of genetically modified Lactococcus lactis for intestinal delivery of human interleukin 10. Nat Biotechnol 2003, 21:785-789.

13. Braat $H$, Rottiers $P$, Hommes DW: A phase I Trial with transgenic bacteria expressing interleukin-10 in Crohn's disease. Clin Gastroenterol Hepatol 2006, 4(6):754-759.

14. Guimarães $V$, Innocentin $S$, Chatel JM, Lefevre F, Langella P, Azevedo V, Miyoshi A: A new plasmid vector for DNA delivery using lactococci. Genet Vaccines Ther 2009, 10(7):4.

15. Innocentin S, Guimarães V, Miyoshi A, Azevedo V, Langella P, Chatel JM, Lefevre F: Lactococcus lactis expressing either Staphylococcus aureus fibronectin-binding protein A or Listeria monocytogenes internalin A can efficiently internalize and deliver DNA in human epithelial cells. Appl Environ Microbiol 2009, 75:4870-4878.

16. Pontes D, Innocentin S, del Carmen S, Franco Almeida J, LeBlanc JG, de Moreno de LeBlanc A, Blugeon S, Cherbuy C, Lefèvre F, Azevedo V, Miyoshi A, Langella P, Chatel JM: Production of fibronectin binding protein $A$ at the surface of Lactococcus lactis increases plasmid transfer in vitro and in vivo. PLoS One 2009, 24:1-9.

17. del Carmen S, Zurita-Turk M, Lima A, Coelho dos Santos JS, Leclerca SY, Chatel JM, Azevedo V, De Moreno de LeBlanc A, Miyoshi A, LeBlanc JG: A novel interleukin-10 DNA mucosal delivery system attenuates intestinal inflammation in a mouse model. EurJ Inflamm 2013, 11(3):641-654.

18. Que YA, Francois P, Haefliger JA, Entenza JM, VaudauX P, Moreillon P: Reassessing the role of Staphylococcus aureus clumping factor and fibronectin-binding protein by expression in Lactococcus lactis. Infect Immunol 2001, 69:6296-6302. 
19. Sambrook J, Fritsch EF, Maniatis T: Molecular cloning: a laboratory manual. Cold Spring Harbor: Cold Spring Harbor Press; 1989.

20. Langella P, Le Loir Y, Ehrlich SD, Gruss A: Efficient plasmid mobilization by pIP501 in Lactococcus lactis subsp. lactis. J Bacteriol 1993, 175:5806-5813.

21. Melgar S, Bjursell M, Gerdin AK, Svensson L, Michaëlson E, Bohlooly-Y M: Mice with experimental colitis show an altered metabolism with decreased metabolic rate. Am J Physiol Gastrointest Liver Physiol 2007, 292(1):G165-G172

22. McCafferty DM, Sihota E, Muscara M, Wallace JL, Keith A, Sharkey KA, Kubes P. Spontaneously developing chronic colitis in IL-10/iNOS double-deficient mice. Am J Physiol Gastrointest Liver Physiol 2000, 279(1):G90-G99.

23. Maron R, Hancock WW, Slavin A, Hattori M, Kuchroo V, Weiner HL: Genetic susceptibility or resistance to autoimmune encephalomyelitis in MHC congenic mice is associated with differential production of pro- and anti-inflammatory cytokines. Int Immunol 1999, 11(9):1573-1580.

24. Alex P, Zachos NC, Nguyen T, Gonzales L, Chen T-E, Conklin LS, Centola M, Li X: Distinct cytokine patterns identified from multiplex profiles of murine dss and tnbs-induced colitis. Inflamm Bowel Dis 2009, 15(3):341-352.

25. Kühn R, Lohler J, Rennick D, Rajewsky K, Muller W: Interleukin-10-deficient mice develop chronic enterocolitis. Cell 1993, 75:263-274.

26. Bhavsar MD, Amiji MM: Oral IL-10 gene delivery in a microsphere-based formulation for local transfection and therapeutic efficacy in inflammatory bowel disease. Gene Ther 2008, 15:1200-1209.

27. Yao J, Wang J-Y, Lai M-G, Li Y-X, Zhu H-M, Shi R-Y, Mo J, Xun A-Y, Jia C-H, Feng J-L, Wang L-S, Zeng W-S, Liu L: Treatment of mice with dextran sulfate sodium-induced colitis with human interleukin 10 secreted by transformed bifidobacterium longum. Mol Pharm 2011, 8:488-497.

28. Pontes DS, de Azevedo MS, Chatel JM, Langella P, Azevedo V, Miyoshi A: Lactococcus lactis as a live vector: heterologous protein production and DNA delivery systems. Protein Expr Purif 2011, 79(2):165-175.

29. Okayasu I, Hatakeyama S, Yamada M, Ohkusa T, Inagaki Y, Nakaya R: A novel method in the induction of reliable experimental acute and chronic ulcerative colitis in mice. Gastroenterology 1990, 98(3):694-702.

30. Hamilton MJ, Sinnamon MJ, Lyng GD, Glickman JN, Wang X, Xing W, Krilis SA, Blumberg RS, Adahi R, Lee DM, Stevens RL: Essential role for mast cell tryptase in acute experimental colitis. Proc Natl Acad Sci 2011, 108(1):290-295.

31. Macpherson AJ, Harris NL: Interactions between commensal intestinal bacteria and the immune system. Nat Rev Immunol 2004, 4(6):478-485.

doi:10.1186/1472-6750-14-73

Cite this article as: Zurita-Turk et al:: Lactococcus lactis carrying the pValac DNA expression vector coding for IL-10 reduces inflammation in a murine model of experimental colitis. BMC Biotechnology 2014 14:73.

\section{Submit your next manuscript to BioMed Central and take full advantage of:}

- Convenient online submission

- Thorough peer review

- No space constraints or color figure charges

- Immediate publication on acceptance

- Inclusion in PubMed, CAS, Scopus and Google Scholar

- Research which is freely available for redistribution 